\title{
O consumo midiático em tempos de convergência no interior do Brasil: aspectos quantitativos da pesquisa com a juventude "rurbana"1
}

\section{Media consumption in times of convergence in the interior of Brazil: quantitative aspects of research with "rurban" youth}

\author{
Matheus Pereira Mattos Felizola \\ Doutor em Ciências Sociais pela Universidade Federal do Rio Grande do Norte (UFRN). Professor do Programa de Pós- \\ Graduação em Comunicação e do Mestrado Profissional em Ciência da Informação da Universidade Federal de Sergipe (UFS). \\ Aracaju (SE), Brasil. E-mail: contato@matheusfelizola.com. \\ Vitor José Braga Mota Gomes \\ Doutor em Comunicação e Cultura Contemporâneas pela Universidade Federal da Bahia (UFBA). Professor do Departamento de \\ Comunicação Social e do Programa de Pós-Graduação em Comunicação da Universidade Federal de Sergipe (UFS). Aracaju \\ (SE), Brasil. E-mail: vitorbragamg@gmail.com.
}

\section{Jane Aparecida Marques}

Livre Docente em Comunicação e Marketing pela Universidade de São Paulo (USP). Professora do curso de graduação em Marketing, do Mestrado Profissional em Empreendedorismo da Faculdade de Economia e Administração e do Programa de PósGraduação Interunidades em Estética e História da Arte, todos da Universidade de São Paulo (USP). São Paulo (SP), Brasil. Email: janemarq@usp.br.

\section{Resumo:}

Neste artigo, com a pesquisa qualitativa e quantitativa envolvendo jovens de 18 a 24 anos, residentes na antiga microrregião de Propriá - interior do estado de Sergipe (Brasil) - visou-se compreender o consumo midiático e cultural dos jovens do denominado "Brasil Profundo". A partir do método quantitativo, obtidos a partir de um questionário estruturado com uma amostra não probabilística de jovens dessa faixa etária, os resultados revelaram que, independentemente das áreas urbanas ou rurais, os participantes da pesquisa possuem acesso constante à internet, e a maioria o faz exclusivamente pelos dispositivos móveis, mesmo que dividindo a atenção com outros meios simultaneamente. Em alguns momentos, o acesso ao rádio e à TV também é feito pela internet, preferencialmente pelos smartphones.

\section{Palavras-chave:}

Jovens; Consumo midiático; Convergência; Rurbanidade.

\section{Abstract:}

In this article, with the qualitative and quantitative research involving young people from 18 to 24 years old, residing in the former micro-region of Propriá - on the countryside of the state of Sergipe (Brazil) - the aim was to understand the media and

\footnotetext{
${ }^{1}$ Trabalho apresentado inicialmente no X Pró-Pesq PP - Encontro de Pesquisadores em Publicidade e Propaganda. De 22 a 24/05/2019. CRP/ECA/USP.
}

INTERIN, v. 26, n. 1, jan./jun. 2021. ISSN: 1980-5276. 
cultural consumption of young people from the so-called "Deep Brazil". Using the quantitative method, obtained from a structured questionnaire with a non-probabilistic sample of young people of this age group, the results revealed that, regardless of urban or rural areas, the research participants have constant access to the internet, and the majority does it exclusively on mobile devices, although they share attention with other media simultaneously. On some occasions, access to the radio and TV is also done via the internet, preferably via smartphones.

\section{Keywords:}

Young people; Media consumption; Convergence; Rurbanity.

\section{Introdução}

Nesta pesquisa, buscamos refletir como é possível perceber traços do consumo cultural contemporâneo no Nordeste brasileiro, especificamente na Microrregião de Propriá ${ }^{2}$, em um contexto em que a divisão tradicional entre rural e urbano não consegue dar conta de compreender as particularidades da região tratada em nossa pesquisa; especialmente quando nos referimos ao público jovem que compõe o objeto de estudo. Diante dessa problemática, cabe-nos trazer o conceito de rurbanidade proposto por Cimadevilla $(2008,2010)$, ao tratar de realidades que mesclam aspectos de áreas rurais e áreas urbanas, e também na relação inversa.

Nesses contextos entendidos como híbridos, socioculturalmente compostos e complexos, Cimadevilla (2010) propõe trabalhar com as mediações, de acordo com a obra de Martín-Barbero (2009) - que busca inverter o olhar antes direcionado às mediações sociais e culturais dos meios de comunicação para olhar a cultura e as mediações a partir da comunicação.

Dessa forma, a partir desse conceito de mediações são exploradas as dimensões da sociabilidade, da tecnicidade e da ritualidade, em um ambiente informacional difuso e descentrado marcado pelas tecnologias digitais, no intuito de compreender a densidade de suas articulações e interfaces. São mediações que, conforme Jacks e

\footnotetext{
${ }^{2}$ Denominação dada até 2017 para a região política na qual a pesquisa foi realizada, abrangendo os municípios de Amparo de São Francisco, Brejo Grande, Canhoba, Cedro de São João, Ilha das Flores, Neópolis, Nossa Senhora de Lourdes, Propriá, Santana do São Francisco e Telha. Em 2018, o Instituto Brasileiro de Geografia e Estatística (IBGE) apresentou uma nova divisão das regiões de Sergipe, ampliando o número de municípios contemplados para essa microrregião.
}

INTERIN, v. 26, n. 1, jan./jun. 2021. ISSN: 1980-5276. 
colaboradoras (2017), ganham maior ou menor relevância de acordo com os objetos e fenômenos estudados.

Em nossa pesquisa, é importante trazer o conceito de rurbanidade por lidarmos com jovens do interior do Brasil, metaforicamente nomeado de "Brasil Profundo" em nosso projeto $^{3}$. Essa denominação é uma adaptação do termo utilizado na obra de Guillermo Bonfil Batalla (1990) e, em nosso caso, a proposta de realizar uma pesquisa com jovens residentes em cidades afastadas dos grandes centros urbanos, como na Microrregião considerada, justifica-se pelo fato de que em nossas pesquisas anteriores - realizadas com jovens da capital, ou seja, em Aracaju (Sergipe) decorrentes de outros dois projetos de pesquisa ${ }^{4}$ - abrangemos os jovens de centros urbanos.

Neste artigo, apresentamos os resultados da pesquisa quantitativa (survey), obtidos de um questionário estruturado aplicado a uma amostra não probabilística de 281 jovens da mesma faixa etária (18 a 24 anos). O objetivo era ampliar o conhecimento acerca da circulação dos meios de comunicação - sejam de contornos massivos ou nas mídias sociais (FAUSTO NETO, 2018) - dos entrevistados de dez municípios nessa região do Nordeste brasileiro.

Nos próximos tópicos, apresentamos a base conceitual que orienta a produção deste artigo: mediações tecnológicas, convergência e rurbanidade. Na sequência, apresentamos a metodologia e a análise dos dados obtidos com a aplicação do questionário e, por fim, as considerações sobre as particularidades do consumo realizado pelos jovens dessa região do Nordeste do Brasil.

\section{Referencial teórico}

No campo da comunicação temos, nos últimos anos, um crescimento nos trabalhos que abordam a temática do consumo midiático dos jovens, especialmente nas questões relacionadas aos aspectos: (1) o consumo dos meios massivos tradicionais, em especial a televisão e o rádio - que figuram entre os mais acessados

\footnotetext{
${ }^{3}$ Projeto "Jovens e Consumo Midiático em Tempos de Convergência: Brasil Profundo", contemplado no Programa Nacional de Cooperação Acadêmica (PROCAD) em 2013 e com previsão de conclusão para o final de 2020.

${ }^{4}$ Projetos "Consumo Cultural dos Jovens Sergipanos em Tempos de Convergência Midiática" (2013 a 2015) e "Jovem e Consumo Cultural em Tempos de Convergência" (2012 a 2015).
}

INTERIN, v. 26, n. 1, jan./jun. 2021. ISSN: 1980-5276.

Matheus Pereira Mattos Felizola; Vitor José Braga Mota Gomes; Jane Aparecida Marques. O consumo midiático em tempos de convergência no interior do Brasil: aspectos quantitativos da pesquisa com a juventude "rurbana". p. 71-85. DOI 10.35168/1980-5276.UTP.interin.2021.Vol26.N1.pp71-85 
por esse público jovem (FRAGA et al., 2017; RONSINI; ROSSATO, 2008; SIFUENTES, 2009; SILVA; MARCONDES, 2014; TOMASI; SIFUENTES, 2013); (2) o atravessamento de sentidos e narrativas da mídia no meio rural (SILVA, 2014; TOLEDO, 2016); (3) o uso de dispositivos móveis no contato com as redes e na produção de conteúdo (ALMEIDA; BELMONTE, 2015; FELIPPI; ESCOSTEGUY, 2017; LOHMANN; MOURO; MOREIRA, 2018; OLIVEIRA; COLFERAI, 2016; SANTOS, 2011); e (4) o consumo, considerando o cenário marcado pela convergência midiática (GOMES; PORTELA, 2015; JACKS; TOALDO; MARQUES, 2017, 2018; RAUBER; MOREIRA, 2018).

É nesse último aspecto que em nossa pesquisa tentamos lançar reflexões, particularizando a região Nordeste. Entendemos a convergência como uma variável importante para pensar sobre o consumo midiático dos jovens. Isto porque, de acordo com Jenkins (2009), esse conceito representa uma transformação cultural, à medida que consumidores são incentivados a procurar novas informações e fazer conexões em meio a conteúdos midiáticos dispersos. Temos, assim, uma abordagem que aponta as Tecnologias e Informação e Comunicação (TICs) como importantes vetores para a reflexão sobre o comportamento das audiências nesse contexto contemporâneo de consumo através das mídias sociais.

A respeito desse cenário de consumo, em um contexto de convergência, Fausto Neto $(2010,2018)$ entende que, na verdade, passamos a observar a circulação de discursos da mídia como uma zona capaz de oferecer um novo lugar de produção, recepção, funcionamento e regulação de sentidos. A pesquisa com jovens nesse "Brasil Profundo" pode expandir o horizonte dessa circulação. Esta tende a ser compreendida como um processo, como consequência da transformação de tecnologias em meios, constituídos na emergência de uma "nova ambiência cujo funcionamento das práticas sociais se dá segundo a atividade interacional dinamizada por complexos feedbacks de natureza não linear" (FAUSTO NETO, 2018, p. 3).

A atenção para a circulação sinaliza, conforme Jenkins e Green (2014), um movimento na direção de um modelo mais participativo de cultura, em que o público não seria mais considerado um grupo de consumidores de mensagens de forma unilateral, mas pessoas que estariam moldando, compartilhando, reconfigurando e 
remixando conteúdos de mídia de maneira que não teriam sido propostas em momentos anteriores do desenvolvimento das TICs.

Antigos modelos de transmissão-recepção de sentidos que comumente operavam sob o crivo de camadas midiáticas, como os meios com contornos massivos, saem de cena e dão lugar às novas modalidades de contatos. Estes contatos se organizam em torno de uma nova dinâmica de circulação, com novas roupagens entrando em cena com a comunicação nos meios digitais, conforme fluxos e circuitos de lógicas não sequenciais e não lineares. A circulação, até então um conceito 'congelado' pela tradição de estudos comunicacionais, como uma problemática esquecida (FAUSTO NETO, 2018), é posta em questão nesse contexto da convergência.

Pensar sobre o consumo, nessa perspectiva, envolve questionar quais as novas formas de existência de determinados grupos sociais, como se relacionam os processos de consumo cultural com a construção de identidades sociais, como o consumo cultural se ressignifica no contexto de globalização e hibridismos (GARCÍA CANCLINI, 2010). Isto porque o consumo midiático perpassa as barreiras do entretenimento e aprofunda-se em um consumo de identidade, tanto individual quanto social (FELIZOLA; BRAGA, 2017, p. 3), na qual o consumo é considerado uma forma de exercer cidadania.

Pretendemos analisar as configurações das práticas e das convivências sociais de jovens de diferentes localidades rurais e urbanas, na interseção de seus contextos de vivências, mediadas ou não pelas tecnologias, baseadas no conceito de rurbanidade (CIMADEVILLA, 2008, 2010). De acordo com o IBGE (2017), 76\% da população brasileira está concentrada em áreas predominantemente urbanas.

Distintamente, os termos rural e urbano restringem o tratamento de questões acerca do espaço sociocultural construído na interconexão entre eles; por isso tratarmos de "rurbanidade". O termo "rurbano", neste caso, serve para evidenciar condições rurais presentes na área urbana e vice-versa. Ou seja, não se trata da extinção do rural, mas da evidência de traços de ruralidade presentes nas cidades ou aspectos de urbanidade nas áreas rurais.

Pretendemos, assim, analisar os usos e apropriações desses jovens, mediados ou não pelas tecnologias digitais, em condições de acesso diferentes daqueles da 
capital, tanto do ponto de vista dos dispositivos tecnológicos quanto das redes de conexão. Nesta pesquisa, entendemos que, residindo em uma área com as características "rurbanas", as práticas sociais e de consumo midiático desses jovens podem revelar especificidades que relacionam os dois âmbitos - rural e urbano -, sem desconsiderar as particularidades dos contextos sociodemográficos em que eles estão inseridos.

\section{Procedimentos metodológicos}

No tocante aos aspectos quantitativos, neste artigo apresentamos os resultados da pesquisa quantitativa, na perspectiva de Fink (2002) e Fowler (2002), obtidos de um questionário estruturado aplicado a 281 jovens de 18 a 24 anos, habitantes das 10 cidades escolhidas na microrregião, residentes em zonas urbanas, rurais, quilombolas e ribeirinhas que compõem a Microrregião de Propriá.

Adotamos o método de survey na pesquisa quantitativa, porque permite conhecer as opiniões, características e comportamentos de determinado grupo social. Para atingirmos tal objetivo, realizamos uma amostra não probabilística por cotas, baseados em Bickman e Rog (1998), com jovens de 18 a 24 anos, residentes na Microrregião de Propriá. O questionário foi estruturado em cinco blocos, com 51 perguntas $^{5}$, perpassando questões binárias, de múltipla escolha, escalas ordinais, escalas nominais e escalas Likert. No Quadro 1 consta a estrutura do questionário.

Realizada a coleta dos dados, utilizamos o software Statistical Package for the Social Sciences (SPSS) para os processamentos que atendessem aos objetivos de pesquisa. A seguir, apresentamos os resultados obtidos dos blocos 1 e 2, após a análise do cruzamento de informações dos dados primários oriundos dos questionários, com aspectos teóricos que abordam temas similares ao nosso, visando confrontar nossos resultados com os de autores que sustentaram o nosso referencial.

\footnotetext{
${ }^{5} \mathrm{O}$ questionário continha um bloco adicional, porém, com o enfoque para questões relacionadas ao empreendedorismo que, por sua vez, compunham outro projeto de pesquisa. Dessa forma, neste artigo não consideramos esse bloco para a análise quantitativa.
}

INTERIN, v. 26, n. 1, jan./jun. 2021. ISSN: 1980-5276.

Matheus Pereira Mattos Felizola; Vitor José Braga Mota Gomes; Jane Aparecida Marques. O consumo midiático em tempos de convergência no interior do Brasil: aspectos quantitativos da pesquisa com a juventude "rurbana". p. 71-85. DOI 10.35168/1980-5276.UTP.interin.2021.Vol26.N1.pp71-85 
Quadro 1 - Estrutura do questionário da pesquisa

$\begin{array}{clc}\text { Divisão } & \text { Conteúdo das questões } & \text { Quantidade } \\ \text { Inicial } & \text { Questão filtro: faixa etária (de 18 a 24 anos) } & 01 \\ \text { Bloco 1 } & \text { Perfil sociodemográfico dos entrevistados } & 11 \\ \text { Bloco 2 } & \begin{array}{l}\text { Práticas de lazer / consumo cultural: tipos e frequência de } \\ \text { consumo de práticas de lazer e consumo cultural }\end{array} & 14 \\ \text { Bloco 3 } & \begin{array}{l}\text { Usos midiáticos: posse de equipamentos, frequência e local de } \\ \text { uso de aparelhos - computadores, smartphones, televisor etc. }\end{array} & 07 \\ \text { Bloco 4 } & \begin{array}{l}\text { Usos das redes sociais: quais utiliza, frequência de uso e } \\ \text { motivações para preferência pelas redes mencionadas }\end{array} & 07 \\ \text { Bloco 5 } & \begin{array}{l}\text { Posse e uso de equipamentos: quais utiliza, frequência e local de } \\ \text { uso }\end{array} & 07 \\ \text { Final } & \text { Informações adicionais (para contato posterior, sendo opcional) }\end{array}$

Fonte: Elaborado pelos autores.

\section{Análise de dados}

Dados da Pesquisa Nacional por Amostra de Domicílios Contínua - PNAD Contínua do Instituto Brasileiro de Geografia e Estatística (IBGE) indicavam que o Brasil, em 2017, possuía 207,7 milhões de habitantes, sendo que a população do Nordeste era de 57,1 milhões de habitantes, o que correspondia a 27,6\% da população brasileira. Segundo esses dados do IBGE (2017), a população estimada de Sergipe seria de 2.288.116 habitantes. Esses números tornavam Sergipe o $22^{\circ}$ estado brasileiro com a maior população residente, mesmo sendo o que possui a menor dimensão territorial - com 21.918,443 km² de extensão. A Microrregião geográfica de Propriá (objeto do nosso estudo), segundo dados do IBGE (2017), possui uma área de 1.014,9 km², e a população estimada para 2017 era de 94.220 habitantes.

\subsection{Perfil sociodemográfico}

Durante o ano de 2017, como já explicitado nos procedimentos metodológicos, foram aplicados 281 questionários nas dez cidades da Microrregião de Propriá, a jovens de 18 a 24 anos; segundo dados da PNAD Contínua (IBGE, 2017), a partir de 
critérios envolvendo jovens na faixa etária de 15 a 19 anos e dos 20 a 24 anos, havia mais de 20 milhões de habitantes nessa localidade pesquisada.

Em relação ao perfil dos amostrados, $48 \%$ dos respondentes eram do sexo masculino e 52\% do sexo feminino, proporção muito próxima à do IBGE (2017), em que as mulheres representavam 51,5\% da população residente no Brasil e os homens, $48,5 \%$. Boa parte dos respondentes $(43,1 \%)$ tinha 18 anos e morava na zona urbana (63\%), embora 31,3\% afirmassem morar na zona rural, 3,4\% em colônia de pescadores e 2,3\% em comunidades quilombolas. É importante observar que, como as cidades da amostra são pequenas, os limites entre as zonas urbanas e rurais também são ínfimos, pois tal qual mencionado por Cimadevilla (2008, 2010), as características do rural estão muito próximas ao urbano e o contrário também acontece.

Em relação à escolaridade dos entrevistados, 63,0\% tinham nível médio incompleto; $28,8 \%$, nível médio completo; $7,5 \%$, nível superior incompleto; e apenas 0,7\%, nível superior completo. Esses dados eram esperados, pois, nos municípios investigados, somente um possuía uma instituição de nível superior. Entre as pessoas de 18 a 24 anos, a taxa de escolarização, em 2017, foi de 31,7\%, e 56,4 milhões de brasileiros que frequentavam escola ou creche, segundo a PNAD Contínua (IBGE, 2017); ou seja, são números próximos aos encontrados no nosso estudo.

O número de jovens entrevistados sem emprego foi de $85,4 \%$; dentre os $14,6 \%$ jovens com empregos formais, o maior percentual $(87,8 \%)$ desses jovens entrevistados era o de trabalhador do comércio. No tocante à geração de renda, $18,1 \%$ dos jovens se consideravam empreendedores, sendo que metade não estava formalizada, e 30,4\% dos jovens eram Microempreendedores Individuais - MEI, o que os configura como negócios de pequeno porte. Por fim, em relação à renda, a maioria dos entrevistados $(56,6 \%)$ possuía renda média de até $\mathrm{R} \$ 1$ mil, e 22,8\% afirmaram não possuir renda própria. Segundo dados da PNAD-Contínua (IBGE, 2017), uma proporção de 56,5\% dos jovens brasileiros possuía algum tipo de rendimento, bem próxima à encontrada na microrregião analisada. 


\subsection{Consumo de mídia}

Em relação às diversas práticas sociais, no consumo de mídias que os respondentes dizem utilizar sempre se destacam: navegar na internet $(66,9 \%)$; em terceiro lugar, citam ouvir música, mesmo que isso seja feito através da internet (57,7\%), e assistir à TV aparece em sexto lugar (48,4\%). Notamos que há outras atividades mencionadas pelos entrevistados como as que sempre fazem, que dependem da proximidade com seus pares, como ir para a casa de parentes $(58,0 \%)$, de amigos ou namorados $(55,5 \%)$ e sair para passear a pé $(55,2 \%)$. Também foram citadas práticas que exigem proximidade física: ir à igreja ou a eventos religiosos $(42,3 \%)$, frequentar festas/bailes $(33,8 \%)$, ir a praças/parques públicos $(32,4 \%)$, ir a bares/restaurantes $(31,7 \%)$, e ir a praias e rios $(25,6 \%)$. Entender o contexto em que esses jovens estão inseridos a partir dessas respostas está muito associado à visão de García Canclini (2009), no que se refere à importância da observação dos aspectos culturais das localidades e da influência destes no ato de consumir. O que pudemos apurar é que nos municípios investigados há poucas instalações de lazer; por exemplo, teatro $(65,1 \%)$, cinema $(59,1 \%)$ e shopping center $(49,8 \%)$ também foram citados, mas não estão disponíveis na microrregião. Ou seja, os jovens precisam se deslocar à capital ou a outro município próximo para poder usufruir desses itens.

Dados da PNAD Contínua (IBGE, 2016) apontam que, aproximadamente, 69\% da população acessam a internet através da banda fixa e $68 \%$ através da internet móvel. A televisão é um meio usado com frequência para 48,4\% dos jovens questionados, principalmente através da televisão a cabo $(37,7 \%)$, da televisão digital $(34,2 \%)$, da televisão analógica $(28,5 \%)$, conforme consta na Tabela 2. Segundo os dados da PNAD Contínua (IBGE, 2016), no Brasil existiam 48,2 milhões de residências com conversor digital, o que correspondia a $71,5 \%$ do total de casas, ao mesmo tempo em que 16,5 milhões de residências não possuíam o aparelho, o que correspondia a 24,5\% do total de casas brasileiras, percentual que pode contemplar municípios de pequeno porte, como é o caso dos que foram investigados neste estudo. 
Tabela 1 - Plataforma(s) que costumam utilizar para assistir à TV - Respostas múltiplas

\begin{tabular}{lcc}
\hline Plataformas & $\mathbf{n}$ & $\mathbf{\%}$ \\
\hline TV a cabo & 106 & $37,7 \%$ \\
TV digital & 96 & $34,2 \%$ \\
TV analógica & 80 & $28,5 \%$ \\
Celular / smartphone / tablet & 30 & $10,7 \%$ \\
Computador/ notebook/ netbook & 13 & $4,6 \%$ \\
Não assiste & 8 & $2,8 \%$ \\
\hline
\end{tabular}

Fonte: Elaborada pelos autores.

Quanto ao conteúdo assistido na televisão, os jovens preferem programas ficcionais - séries/telenovelas $(54,4 \%)$ e filmes (49,5\%); seguem os noticiários televisivos $(30,2 \%)$, os programas esportivos $(27,8 \%)$ e, em seguida, voltam os ficcionais desenhos animados $(26,7 \%)$.

Os respondentes também ouvem música, principalmente em seus celulares ou tablets $(73,1 \%)$, aparelhos de som em casa $(47,7 \%)$ e aparelhos de rádio $(25,8)$. Em relação ao formato de músicas, a prática mais comum é o consumo através do download (58,9\%), seguido do acesso pela internet (39,3\%) e por meio de CDs e DVDs $(31,1 \%)$. Meios de comunicação de massa tradicionais, como jornais $(8,6 \%)$ e revistas $(13,7 \%)$ digitais são menos consumidos pelos jovens entrevistados, que normalmente preferem as versões impressas dos jornais (56,8\%). E também as revistas digitais são citadas com um pouco de distinção em relação às impressas $(51,9 \%)$.

Tabela 2 - Formato(s)/meio(s) mais consumidos para assistir a filmes - Respostas múltiplas

\begin{tabular}{lccc}
\hline Formatos/meios & $\mathbf{n}$ & $\%$ \\
\hline TV aberta & 106 & $38,5 \%$ \\
TV por assinatura & 93 & $33,8 \%$ \\
Assiste on-line (YouTube, Mega Filmes e sites) & 89 & $32,4 \%$ \\
Baixa/ faz download & 65 & $23,6 \%$ \\
Plataformas de streaming (Netflix, HBO Go, Crackle etc.) & 31 & $11,3 \%$ \\
Compra DVD / pen drive "pirata" & 30 & $10,9 \%$ \\
Cinema & 17 & $6,2 \%$ \\
Compra DVD original & 14 & $5,1 \%$ \\
Aluga DVD & 4 & $1,5 \%$ \\
\hline
\end{tabular}

Fonte: Elaborada pelos autores.

INTERIN, v. 26, n. 1, jan./jun. 2021. ISSN: 1980-5276. 
Em relação aos filmes, a maior parte dos respondentes afirmou assistir na televisão aberta $(38,5 \%)$ e um pouco menos $(33,8 \%)$ utiliza televisão fechada ou paga. Notamos que o consumo midiático desses jovens está apoiado pela convergência midiática (JENKINS, 2009; JENKINS; GREEN, 2014); ou seja, já não dependem unicamente da televisão para assistir a filmes.

Outro dado interessante, no tocante aos filmes, foi a menção ao cinema, ainda que não exista um na região. O que nos revela pistas de como os jovens da localidade pesquisada circulam por várias cidades - mesmo fora da microrregião - para terem acesso a bens de consumo, a exemplo dos produtos midiáticos (WEISHEIMER, 2005).

Já no tocante aos livros, a maior parte dos jovens ainda prefere as versões impressas, com 40,2\%, seguido do consumo por meio de aplicativos nos celulares, $32,7 \%$. Este último deve ser observado de perto, por ser bastante expressivo, ao considerarmos o número de leitores em outros formatos que não os tradicionais impressos.

Tabela 3 - Suporte(s) utilizados para leitura de livros - Respostas múltiplas

\begin{tabular}{lcc}
\hline Suportes & $\mathbf{n}$ & $\boldsymbol{\%}$ \\
\hline Impresso & 113 & $40,2 \%$ \\
Aplicativo no celular / smartphone & 92 & $32,7 \%$ \\
Computador / notebook / netbook & 29 & $10,3 \%$ \\
Audiolivro & 12 & $4,3 \%$ \\
Leitor digital (Kindle, Kobo, Lev etc.) & 4 & $1,4 \%$ \\
Aplicativo no tablet & 2 &, $7 \%$ \\
Não leio & 59 & $21,0 \%$ \\
\hline
\end{tabular}

Fonte: Elaborada pelos autores.

\section{Considerações Finais}

Elegemos estudar o consumo cultural e midiático de jovens residentes no interior do estado de Sergipe, mais especificamente da Microrregião de Propriá, que consideramos área "rurbana", segundo Cimadevilla (2008, 2010, 2014). A partir de investigação preliminar - teórica e documental - sobre os municípios investigados, 
sabíamos de antemão que as opções culturais eram restritivas e por isso foram necessárias algumas idas a campo.

Pudemos constatar que a perspectiva de Weisheimer (2005) está presente no contexto investigado, pois os processos migratórios, por exemplo, são frequentes entre os jovens e/ou com seus pares. Muitos residentes dessa Microrregião destacaram que precisam sair para trabalhar ou estudar em município próximo, o que pode restringir, ao menos temporariamente, o convívio familiar e a proximidade com os amigos circunvizinhos. Fenômeno que se aproxima também da percepção do Cimadevilla (2008, 2010, 2014) na intensa relação "rurbana".

Os investigados também registraram a falta de opções culturais, o que favorece o contato pessoal e exige também deslocamentos para municípios próximos ou para a capital do estado, o que nem sempre é viável. O fato é que esses jovens comumente ficam “invisíveis socialmente” e, portanto, excluídos de direitos sociais e de políticas públicas.

Nessas condições, o consumo midiático, para muitos, acaba centralizado nas atividades digitais, tanto para o acesso dos meios massivos tradicionais quanto das ferramentas on-line, sendo que estas são mais acessadas pelos dispositivos móveis, principalmente pelos smartphones. Destacamos que navegar na internet é citado pelos respondentes como a principal atividade de lazer, seguida por ouvir música (que pode ser na internet), ir para a casa de parentes, dos amigos/namorados e sair para passear a pé. Esses últimos aspectos, particularmente, indicam que a proximidade física é comum entre esses jovens e a relevância nas trocas com os grupos primários.

Notamos que assistir à TV tem muita importância para os respondentes, sendo citada como a principal fonte para buscarem informações sobre o que está acontecendo nas proximidades, no estado ou no mundo. Esse consumo televisivo se dá muitas vezes em um processo convergente, no qual eles fazem uso de diversos aparelhos smartphones, computadores e aparelhos de televisão - para o acesso. Temos assim uma forma de consumo que, com base na compreensão de Jenkins (2009), tem a centralidade da mídia massiva, mas ao mesmo tempo os sentidos são discutidos com suas redes sociais, especialmente nas ambiências digitais de sites de redes sociais e aplicativos. 
As mídias sociais (Facebook e WhatsApp) são mencionadas com frequência pelos jovens entrevistados, pois estas direcionam a atenção para conteúdos que atendam aos interesses particulares. São esses os aplicativos acessados pelos jovens participantes da nossa pesquisa, várias vezes ao dia, principalmente no período noturno, quando eles têm mais tempo livre. São as mídias sociais que os jovens utilizam para contato com seus grupos primários (família, amigos), os mais constantes (colegas de trabalho e de escola), mas também para fazer novos contatos e/ou novas amizades. Destacamos, assim, a centralidade de dispositivos móveis - celulares e smartphones - no cotidiano de nosso público-alvo, promovendo tanto as interações sociais quanto o consumo midiático e cultural. Parte dessa centralidade ocorre pela frequência do uso por essa parcela da população brasileira, principalmente pela baixa oferta cultural e midiática na região em que os jovens pesquisados moram.

\section{REFERÊNCIAS}

ALMEIDA, C. D. de; BELMONTE, A. Os jovens e o uso do celular na fronteira. Anais do XXXVIII Congresso Brasileiro de Ciências da Comunicação, v. 1, $\mathrm{n}^{\circ}$, p. $1-15,2015$.

BICKMAN, L.; ROG, D. Handbook of applied social research methods. 2. ed. Thousand Oaks: Sage, 1998.

BONFIL BATALLA, G. B. México profundo: una civilización negada. 2. ed. Cidade do México: Grijalbo, 1990.

CIMADEVILLA, G. !Bienvenidos a la rurbanidad! Disponível em: <https://www.pagina12.com.ar/diario/laventana/26-103315-2008-04-30.html>.

CIMADEVILLA, G. La Cuestión Rurbana: Apuntes para una entrada comunicacional. Intercom - Revista Brasileira de Ciências da Comunicação, v. $33, n^{\circ} 2$, p. 73-85, 2010.

CIMADEVILLA, G. Las formas de la rurbanidad: anuncios e imágenes. Anais do XII ALAIC - Asociación Latinoamericana de Investigadores de la Comunicación, v. 1, $\mathrm{n}^{\circ}$ 1, 2014.

FAUSTO NETO, A. As bordas da circulação. Alceu, v. 10, nº 1, p. 55-69, 2010.

FAUSTO NETO, A. Circulação: Trajetos conceituais. Rizoma, v. 6, nº 2, p. 8-40, 2018.

FELIPPI, A. C. T.; ESCOSTEGUY, A. C. D. Juventude Rural e Novas Formas de INTERIN, v. 26, n. 1, jan./jun. 2021. ISSN: 1980-5276.

Matheus Pereira Mattos Felizola; Vitor José Braga Mota Gomes; Jane Aparecida Marques. O consumo midiático em tempos de convergência no interior do Brasil: aspectos quantitativos da pesquisa com a juventude "rurbana". p. 71-85. DOI 10.35168/1980-5276.UTP.interin.2021.Vol26.N1.pp71-85 
Sociabilidade: um estudo do uso do celular no Sul do Brasil. Revista

Latinoamericana de Ciencias de La Comunicación, v. 14, nº 26, p. 140-150, 2017.

FELIZOLA, M. P. M.; BRAGA, V. Consumo Midiático em um Brasil profundo: uma incursão no interior sergipano. Anais do $4^{\circ}$ Congresso Brasileiro de Ciências da Comunicação, v. 1, no 1, p. 1-14, 2017.

FINK, A. The survey kit. 2. ed. Beverly Hills: Sage, 2002.

FOWLER, F. J. Survey Research Methods. In: Sage. $3^{\text {a }}$ ed. Beverly Hills: Sage, 2002.

FRAGA, K. DE L. et al. A relação das sociedades rurais com o rádio na contemporaneidade. Espacios, v. 38, nº 4, p. 19-30, 2017.

GARCÍA CANCLINI, N. Consumidores e cidadãos: conflitos multiculturais da globalização. $1^{a}$ ed. Rio de Janeiro: Editora UFRJ, 2010.

GOMES, M.; PORTELA, K. G. B. Os usos sociais das mídias em tempo de convergência. Anais do XXXVIII Congresso Brasileiro de Ciências da Comunicação, v. 1, no 1, p. 1-15, 2015.

JACKS, N. et al. Jovens do "Brasil Profundo": explorações sobre usos tecnológicos e consumo midiático em Tavares (RS). Anais do XXVI Encontro Anual da Compós. São Paulo: Compós, 2017. Disponível em:

$<$ https://www.lume.ufrgs.br/bitstream/handle/10183/166195/001046530.pdf?sequenc $\mathrm{e}=1>$

JACKS, N.; TOALDO, M.; MARQUES, J. Jovens rurbanos e mediações tecnológicas: práticas e convivências sociais contemporâneas. Cuadernos del Claeh, v. 36, no 106, p. 101-123, 2017.

JACKS, N.; TOALDO, M.; MARQUES, J. Jovens Rurbanos: Consumo Midiático no "Brasil Profundo". Anais do 410 Congresso Brasileiro de Ciências da Comunicação, v. 1, n⿳0 1, p. 1-16, 2018.

JENKINS, H. Cultura da Convergência. $1^{a}$ ed. São Paulo: Aleph, 2009.

JENKINS, H.; GREEN, J.; FORD, S. Cultura da conexão: criando valor e significado por meio da mídia propagável. $1^{\text {a }}$ ed. São Paulo: Aleph, 2014.

LOHMANN, L. B.; MOURO, M. C.; MOREIRA, B. D. Consumo Tecnológico e Midiático: uma análise de dados referentes à zona rural de Jangada - MT. Anais do $4^{\circ}$ Congresso Brasileiro de Ciências da Comunicação, v. 1, nº 1, p. 1-15, 2018.

MARTIN-BARBERO, J. Dos meios às mediações: Comunicação, cultura e hegemonia. $4^{\text {a }}$ ed. Rio de Janeiro: Editora UFRJ, 2009.

OLIVEIRA, A. D. de; COLFERAI, S. A. Geração Digital: Cenários e condições dos usos de recursos multimídias do jovem de Vilhena/RO. Anais do XV Congresso de Ciências da Comunicação na Região Norte, v. 1, nº 1, p. 1-13, 2016. 
RAUBER, T. M.; MOREIRA, B. D. Jovem e o Consumo Midiático em Tempos de Convergência: Serra de São Vicente/MT. Anais do $41^{\circ}$ Congresso Brasileiro de Ciências da Comunicação Congresso Brasileiro de Ciências da Comunicação, v. $1, \mathrm{n}^{\circ} 1$, p. 1-15, 2018.

RONSINI, V. M.; ROSSATO, A. O popular e a leitura radiofônica: um estudo de recepção entre jovens camponeses. Fronteiras, v. 10, nº 1, p. 1-9, 2008.

SANTOS, M. S. T. Juventude Rural em Tempo de Redes Sociais. Anais do XXXIV Congresso Brasileiro de Ciências da Comunicação, v. 1, nº 1, p. 1-14, 2011.

SIFUENTES, L. A recepção televisiva por jovens rurais: Um estudo sobre as representações do campo e da cidade. Anais do $\mathbf{X}$ Congresso de Ciências da Comunicação na Região Sul, v. 1, no 1, p. 1-15, 2009.

SILVA, A. C. de A. M. da; MARCONDES, V. Mulheres Camponesas e Cidadania: Um aporte teórico sobre o consumo midiático entre integrantes do Movimento de Mulheres Camponesas de Santa Catarina (MMC/SC). Gênero, v. 15, nº 1, p. 11-28, 2014.

SILVA, R. D. da. Atravessamento de sentidos e narrativas televisivas no meio rural: interlocuções e valores na dicotomia rural/urbano. Anais do III Colóquio Semiótica das Mídias, v. 1, nº 1, p. 1-16, 2014.

TOLEDO, R. V. C. de. Adolescente, comunicação e cultura: realidades socioculturais e suas formas de comunicabilidade. Anais da II Bienal Iberoamericana de Infancias y Juventude, v. 1, nº 1, p. 742-748, 2016.

TOMASI, A. P.; SIFUENTES, L. Consumo de mídia: O jornalismo econômico inserido na realidade social do jovem no oeste catarinense. Anais do XIV Congresso de Ciências da Comunicação na Região Sul, v. 1, no 1, p. 1-12, 2013.

WEISHEIMER, N. Juventudes rurais: mapa de estudos recentes. $1^{a}$ ed. Brasília: Ministério do Desenvolvimento Agrário, 2005.

Recebido em: 15/06/2020

Aceito em: 15/10/2020

INTERIN, v. 26, n. 1, jan./jun. 2021. ISSN: 1980-5276.

Matheus Pereira Mattos Felizola; Vitor José Braga Mota Gomes; Jane Aparecida Marques. O consumo midiático em tempos de convergência no interior do Brasil: aspectos quantitativos da pesquisa com a juventude "rurbana". p. 71-85. DOI 10.35168/1980-5276.UTP.interin.2021.Vol26.N1.pp71-85 